\title{
Synthesis of Photobase Generators Based on Proazaphosphatrane - Tetraarylborate Complex for i-Line Photopatterning
}

\author{
Yuji Shibasaki*, Junichi Sato and Yoshiyuki Oishi \\ Department of Chemistry \& Bioengineering, Faculty of Engineering, \\ Iwate University, 4-3-5, Ueda, Morioka, Iwate 020-8551, Japan \\ yshibasa@iwate-u.ac.jp
}

\section{Introduction}

Photopolymers are the key technology to support our daily life in a variety fields such as coatings, inks, and photoresists, adhesives, imaging, and stereo-photolithography [1]. A photobase generator (PBG) is a promising photoactive compound in industry [2], but the studies of PBGs are scarce. So far, several types of PBGs were reported such as the cobalt-amine complex [3], $o$-nitrobenzoyl carbamates and urethanes [4], $o$-acyloximes [5], blocked aniline [6], and benzoin carbamate [7] Recently bicyclic guanidium tetraphenylborate complexes as a super-photobase generator $\left(\mathrm{pK}_{\mathrm{a}}\right.$ 26) were synthesized and applied to the formation of photopolymer system for $250 \mathrm{~nm}$ photopatterning [8]. Here we report novel PBGs based on proazaphosphatrane $\left(\mathrm{pK}_{\mathrm{a}}>33\right)$ and tetraaryl borate complex for i-line photopatterning system.

\section{Experimental}

\subsection{Materials}

Diethyl ether and tetrahydrofurane were dried over sodium and distilled prior to use.
The epoxy resin (jER-1001) was kindly donated from Mitsubishi Chemical Corporation. The PMA-co-PMMA (0.016: 1) copolymer $\left(M_{\mathrm{n}} \sim 15,000\right)$ was purchased from Aldrich. Other solvents and reagents were purchased and used without further purification.

\subsection{Characterization}

Nuclear magnetic resonance (NMR) was performed on a Bruker AC-400P spectrometer. Uv-vis spectra were recorded on Jasco V-570 UV/VIS/NIR spectrophotometer. The film thickness on silicon wafers was measured by Veeco Instrument Dektak ${ }^{3}$ surface profiler.

\subsection{Photosensitivity}

jER1001 (1.54 g, $80 \quad \mathrm{wt} \%)$ and PMA-co-PMMA $(0.38 \mathrm{~g}, 20 \mathrm{wt} \%)$ were dissolved in THF $(20 \mathrm{~mL})$. Into the polymer solution, PBG (5 wt $\%$ to the matrix polymers) were added to prepare a photosensitive polymer solution. The solution was dropped onto the silicon wafer, spin-coated at $500 \mathrm{rpm}$ for $10 \mathrm{~s}$, prebaked at $80{ }^{\circ} \mathrm{C}$ for $5 \mathrm{~min}$, irradiated with $365 \mathrm{~nm}$ light for the set time, and

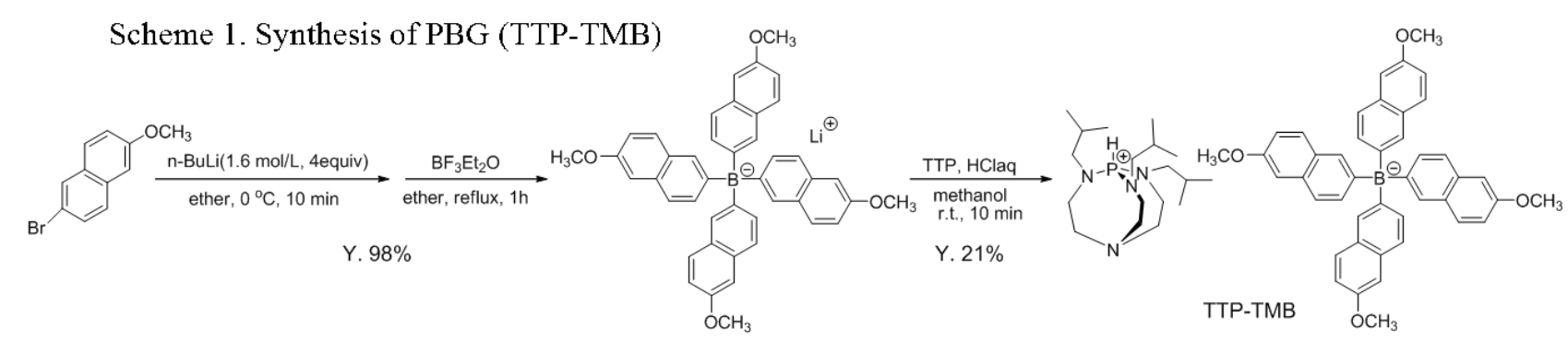

\begin{tabular}{llrr}
\hline Received & April & 2, & 2012 \\
Accepted & May & 10, & 2012
\end{tabular}


postbaked at $180{ }^{\circ} \mathrm{C}$ for $30 \mathrm{~min}$. The film was developed with dry THF for $30 \mathrm{~s}$ to make a negative image. A characteristic curve was obtained by plotting a normalized film thickness as a function of exposure dose $\left(\mathrm{mJ} / \mathrm{cm}^{2}\right)$.

2.4 Synthesis of PBGs $\left(\mathrm{P}\left(i-\mathrm{BuNCH}_{2} \mathrm{CH}_{2}\right)_{3} \mathrm{~N}\right.$ tetrakis(2-naphthyl borate) (TTP-TMB)

Tetrakis(6-methoxynaphthyl)borate (TMB) $(1.1 \mathrm{mmol})$ was dissolved in water $(5 \mathrm{~mL})$. In a dark room, a proazaphosphatrane $\mathrm{P}\left(i-\mathrm{BuNCH}_{2} \mathrm{CH}_{2}\right)_{3} \mathrm{~N}$ (TTP) $(0.34 \mathrm{~g}, 1.0 \mathrm{mmol})$ was dissolved in methanol $(10 \mathrm{~mL})$, and the solution was acidified with $\mathrm{HCl}$ aqueous solution. Into the solution the borate solution in water was added in one-portion, stirred for 10 min, and the white precipitate was collected by filtration. This was recrystallized from methanol, and dried at $60{ }^{\circ} \mathrm{C}$ for $6 \mathrm{~h}$ under vacuum to afford the title compound as white plates. Yield $0.094 \mathrm{~g}(12 \%), \mathrm{T}_{\mathrm{m}}=144-145^{\circ} \mathrm{C}$.

\section{Results and discussion}

\subsection{Synthesis of PBGs}

The PBGs were prepared by the lithiation of aryl bromide with $\mathrm{n}-\mathrm{BuLi}$, followed by the cation exchange reaction with TTP-HCl complex in water as illustrated in Scheme 1. The compound was characterized by ${ }^{1} \mathrm{H},{ }^{11} \mathrm{~B}$, and ${ }^{13} \mathrm{C}$ NMR spectroscopy.

\subsection{Photo absorption}

Figure 1 shows the UV-vis spectra of prepared PBGs in DMAc $(0.1 \mathrm{mM})$. The TTP-tetraphenyl borate complex only shows the $\lambda_{\max }$ at $265 \mathrm{~nm}$, and this value is effectively shifted up to $345 \mathrm{~nm}$ for TTP-TMB. Although the $\lambda_{\max }$ of the compound is still far from i-line, its absorption edge is on the wavelength. Therefore, we determined to use this compound for the fabrication of a photopolymer system.

\subsection{Photolithography evaluation}

To check the photobase generation ability of TTP-TMB, the photopolymer was fabricated using epoxy resin (jER1001) and PMA-co-PMMA (0.016: 1) copolymer as the matrix. The detailed procedures are summarized in Figure 2. The polymer mixture was dissolved in THF, and TTP-TMB (ca. 5 wt $\%$ to the matrix polymer) was added in a dark room. The solution was spin-coated on a silicon wafer, and prebaked at $80{ }^{\circ} \mathrm{C}$ for $5 \mathrm{~min}$, irradiated with $365-\mathrm{nm}$ light for the set time, PEB at 80 to $190{ }^{\circ} \mathrm{C}$ for $30 \mathrm{~min}$, and developed with THF for $5 \mathrm{~s}$. The suitable PEB temperature to obtain enough dissolution contrast between exposed and unexposed areas was $180{ }^{\circ} \mathrm{C}$. From these results, the photosensitivity curve of the $c a 1 \mu \mathrm{m}$ photopolymer film was plotted as shown in Figure 3. In this preliminary experiment, the high sensitivity of $45 \mathrm{~mJ} / \mathrm{cm}^{2}$ and the good contrast of 3.7 were obtained.

Figure 4 depicts the optical microscopic image of the photopatterned film. About $10 \mu \mathrm{m}$ clear line and space resolution was observed, indicating the high usability of the PBG.

Notably, in the similar photopatterning conditions, Irgacure 907 and DNCDP [9] are both ineffective to obtain a clear photo-image. These results again indicated the high usability of the PBG, TTP-TMB, which generates a super base TTP (pKa > 33) after irradiation of 365-nm industrial standard light.

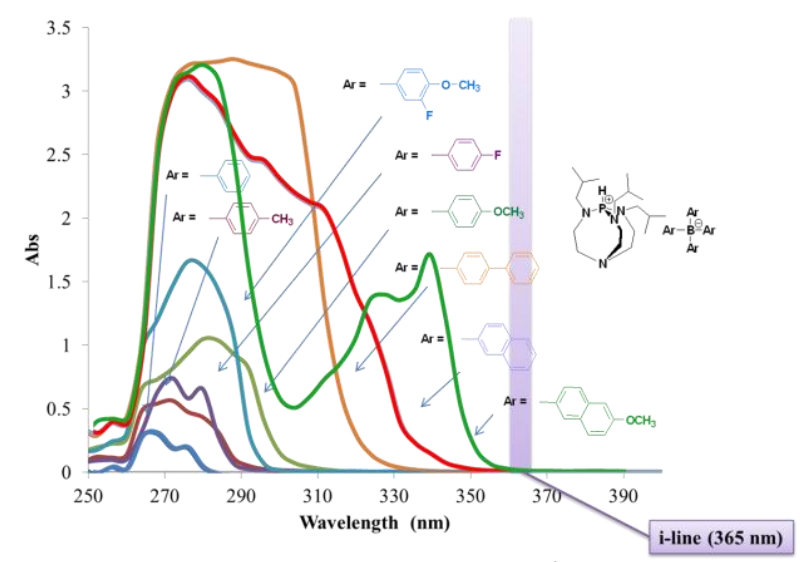

Figure 1. UV-vis spectra of PBGs $\left(1.0 \times 10^{-4} \mathrm{M}\right)$ in DMAc. 


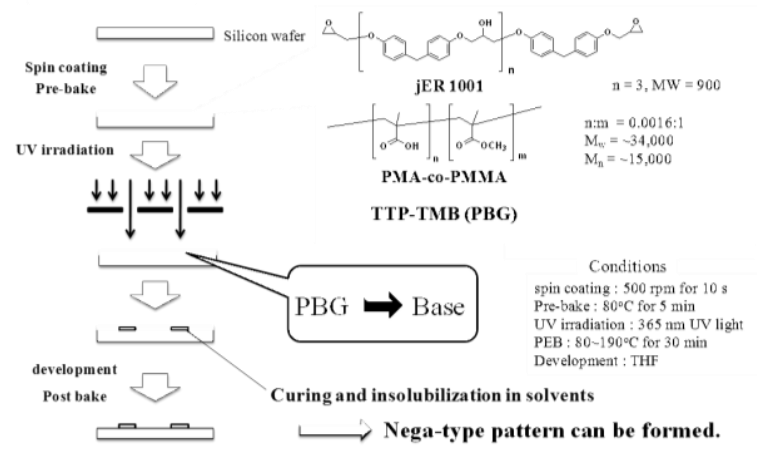

Figure 2. Photopatterning procedures

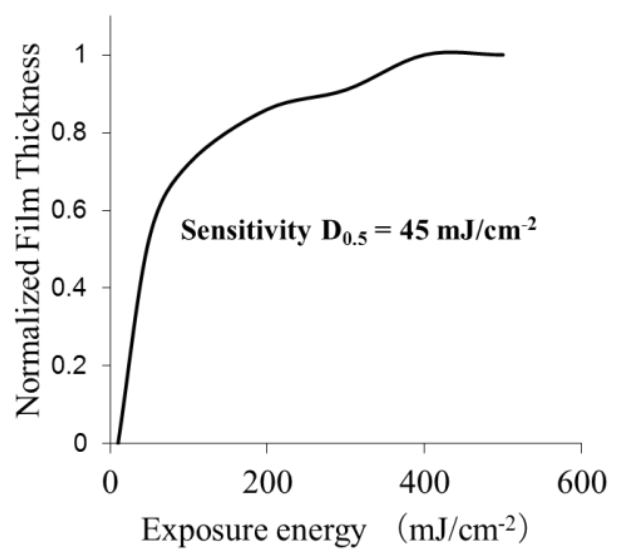

Figure 3. Photosensitivity curve

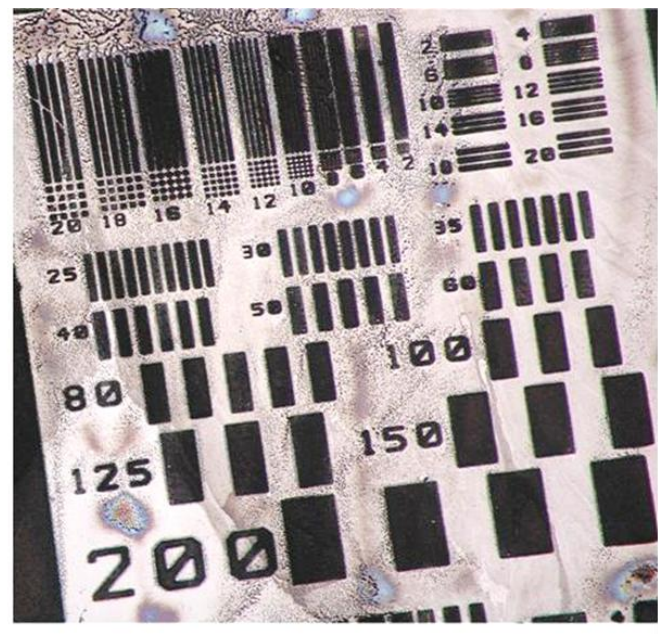

Figure 4. Optical micrograph image fabricated from epoxy resin - PMA-PMMA (20:80). The polymer solution in THF was spincoated at 500 $\mathrm{rpm}$ for $10 \mathrm{~s}$, prebaked at $80^{\circ} \mathrm{C}$ for $5 \mathrm{~min}$, irradiated with $365-\mathrm{nm}$ light at $400 \mathrm{~mJ} / \mathrm{cm}^{-2}$, PEB at $180^{\circ} \mathrm{C}$ for $15 \mathrm{~min}$, and developed with THF for $10 \mathrm{~s}$.

\section{Conclusion}

We fabricated a novel i-linephotopatternable material based on epoxy resin and $\mathrm{PMA}_{0.016}-\mathrm{co}-\mathrm{PMMA}_{1}$ in conjunction with a PBG, $\left(\mathrm{P}\left(i \text {-BuNCH} \mathrm{CH}_{2}\right)_{3} \mathrm{~N}\right.$-tetrakis(2-naphthyl borate), and demonstrated the preliminary photopatterning experiment using it. The photopolymer system shows a high sensitivity and good contrast of $45 \mathrm{~mJ} / \mathrm{cm}^{-2}$ and 3.7 , respectively. The clear negative-tone image of $10 \mu \mathrm{m}$ line and space resolution was obtained on a silicon wafer after the irradiation of 365-nm UV light, followed by PEB at $180{ }^{\circ} \mathrm{C}$ for $15 \mathrm{~min}$ and the development with THF for $10 \mathrm{~s}$.

\section{Reference}

1. R. W. Peiffer, ACS Symposium Series, 673 (1997), 1.

2. K. Suyama, M. Shirai, Trend. Polym. Sci., 34 (2009) 194.

3. C. Kutal,C. G. Willson, J. Electrochem. Soc., 134 (1987) 2280.

4. (a) J. F. Cameron, C. G. Willson, J. M. J. Fre' chet, J. Am. Chem. Soc., 118 (1996) 12925. (b) J. F. Cameron, J. M. J. Fre' chet, J. Am. Chem. Soc., 113 (199) 4303.

5. K. Ito, S. Yoshitaka, Y. Kawata, K. Ito, M. Tsunooka, Can. J. Chem., 73 (1995) 1924.

6. T. Nishkubo, A. Kameyama, Polym. J., 25 (1993) 421.

7. J. F. Cameron, C. G. Willson, J. M. J. Fre' chet, J. Chem. Soc. Perkin Trans. 1 (1997) 2429.

8. X. S. Jian, J. P. Gao, Z. Y. Wang, J. Am. Chem. Soc., 130 (2009) 8130.

9. A. Mochizuki, T. Teranishi, M. Ueda, Macromolecules, 28 (1995) 365. 